\title{
Spatial and temporal patterns of root distribution in developing stands of four woody crop species grown with drip irrigation and fertilization
}

\author{
Mark Coleman
}

Received: 19 November 2006/Accepted: 29 March 2007/ Published online: 7 September 2007

C. Springer Science + Business Media B.V. 2007

\begin{abstract}
In forest trees, roots mediate such significant carbon fluxes as primary production and soil $\mathrm{CO}_{2}$ efflux. Despite the central role of roots in these critical processes, information on root distribution during stand establishment is limited, yet must be described to accurately predict how various forest types, which are growing with a range of resource limitations, might respond to environmental change. This study reports root length density and biomass development in young stands of eastern cottonwood (Populus deltoidies Bartr.) and American sycamore (Platanus occidentalis L.) that have narrow, high resource site requirements, and compares them with sweetgum (Liquidambar styraciflua L.) and loblolly pine (Pinus taeda L.), which have more robust site requirements. Fine roots $(<1 \mathrm{~mm})$, medium roots ( 1 to $5 \mathrm{~mm}$ ) and coarse roots ( $>5 \mathrm{~mm}$ ) were sampled to determine spatial distribu-
\end{abstract}

Responsible Editor: Tibor Kalapos.

The US Government has the right to retain a nonexclusive, royalty-free license in and to any copyright covering this paper. Mention of a commercial or proprietary product does not constitute endorsement or recommendation by the USDA Forest Service.

M. Coleman $(\bowtie)$

Southern Research Station, USDA Forest Service,

Savannah River, 241 Gateway Drive,

Aiken, SC 29803, USA

e-mail: mcoleman01@fs.fed.us tion in response to fertilizer and irrigation treatments delivered through drip irrigation tubes. Root length density and biomass were predominately controlled by stand development, depth and proximity to drip tubes. After accounting for this spatial and temporal variation, there was a significant increase in RLD with fertilization and irrigation for all genotypes. The response to fertilization was greater than that of irrigation. Both fine and coarse roots responded positively to resources delivered through the drip tube, indicating a wholeroot-system response to resource enrichment and not just a feeder root response. The plastic response to drip tube water and nutrient enrichment demonstrate the capability of root systems to respond to supply heterogeneity by increasing acquisition surface. Fineroot biomass, root density and specific root length were greater for broadleaved species than pine. Roots of all genotypes explored the rooting volume within 2 years, but this occurred faster and to higher root length densities in broadleaved species, indicating they had greater initial opportunity for resource acquisition than pine. Sweetgum's root characteristics and its response to resource availability were similar to the other broadleaved species, despite its functional resemblance to pine regarding robust site requirements. It was concluded that genotypes, irrigation and fertilization significantly influenced tree root system development, which varied spatially in response to resource-supply heterogeneity created by drip tubes. Knowledge of spatial and temporal patterns of root distribution in these stands will 
be used to interpret nutrient acquisition and soil respiration measurements.

Keywords Functional groups - Root length density .

Soil heterogeneity Stand development .

Vertical root distribution - Woody crops

$\begin{array}{ll}\text { Abbreviations } \\ \text { SRL } & \text { specific root length } \\ \text { RLD } & \text { root length density } \\ \text { C } & \text { control treatment } \\ \text { I } & \text { irrigation } \\ \text { F } & \text { fertilization } \\ \text { IF } & \text { irrigation plus fertilization } \\ x & \begin{array}{l}\text { horizontal distance from the tree parallel to } \\ \text { the drip tube }\end{array} \\ y & \begin{array}{l}\text { horizontal distance from the tree perpendic- } \\ \text { ular to the drip tube }\end{array} \\ \text { ST66 } & \begin{array}{l}\text { eastern cottonwood clone from Issaquena } \\ \text { County, MS, USA }\end{array} \\ \text { S7C15 } & \begin{array}{l}\text { eastern cottonwood clone from Brazos } \\ \text { County, TX, USA }\end{array}\end{array}$

\section{Introduction}

Root processes mediate the two largest fluxes in the forest carbon cycle: primary production and soil $\mathrm{CO}_{2}$ efflux. Production is largely determine by root acquisition of soil nutrients and water (Waring and Schlesinger 1985) and over half of soil $\mathrm{CO}_{2}$ efflux can be composed of recently assimilated carbon substrates respired by roots and rhizosphere organisms (Ryan and Law 2005; Trumbore 2006). Despite the significance of root processes in carbon cycling, our understanding of basic characteristics, such as the distribution and dynamics of roots, is minimal. We still lack adequate information on forest tree species differences in root quantity and distribution, how these factors change during the development of forest stands and the effects of soil resource limitations. Yet, predicting the impacts of environmental change on terrestrial ecosystems will require detailed description of root distribution because of their essential role in mediating major carbon fluxes (Chapin and Ruess 2001).

Root distribution is an indicator of the spatial distribution of tree root activity because increased root length density (RLD) results in proportional increases in water uptake (Boyer 1985), nutrient acquisition (Nye and Tinker 1977) and soil respiration (Luo and Zhou 2006); therefore, information on distribution is essential for understanding the dynamics of root activity. Root distribution and activity vary spatially and temporally. For example, root processes are greater at the soil surface than at depth because root length density (Gale and Grigal 1987; Jackson et al. 1996), nutrient concentrations and nutrient cycling (Connell et al. 1995; Jobbagy and Jackson 2001; Patra et al. 1999) are higher in surface layers, yet these vary substantially among ecosystems. Likewise, patchy horizontal resource distribution results in variable root development and uptake capacity, with different functional groups responding in distinct ways to resource heterogeneity (Hodge 2004; Robinson 1994). Temporal responses are equally important to define. For instance, root systems proliferate during forest stand establishment in proportion to plant production (Adegbidi et al. 2004; Hughes and Gandar 1993; Misra et al. 1998; O’Grady et al. 2005), indicating increased root system capacity for nutrient and water acquisition. Defining spatial and temporal variation is essential to determining the relative magnitude of genetic and environmental factors.

The morphology of root systems and the responsiveness to heterogeneous soil conditions is expected to vary among tree species. Root system morphology, including individual root size, the architectural display, and RLD varies among species, and these various species characteristics are related to the functional group in which the species belongs (Fitter 1991; Pregitzer et al. 2002). Broadleaved deciduous species are distinct from needle-leaved evergreen species (Comas and Eissenstat 2004; Einsmann et al. 1999), yet other functional categories may also influence root characteristics. Stress tolerant tree species such as those living on upland well drained soils or those with robust site requirements are expected to have roots with larger diameters lower specific root length (SRL), lower specific respiration rates (Comas and Eissenstat 2004; Reich et al. 1998) and lower turnover rates (Chapin 1980). They are also expected to be less responsive to heterogeneous resource availability (Einsmann et al. 1999; Mou et al. 1995) and have greater dependence on symbiotic mycorrhizal associations (Harley and Smith 1983). Whereas fast-growing species adapted to more favorable habitats with abundant moisture and nutrients, such as those restricted to bottomland or alluvial sites, are expected to have shorter fine-root life span, be more responsive to patchy resource availability, 
and less dependent upon mycorrhizal associations. Tests of these relationships in mature trees are rare because of sampling and site uniformity difficulties, which lead to conflicting results (e.g. Hendricks et al. 1993). For instance, it is not clear if genetics or environmental factors exert predominate control over root system characteristics. Comparing species from distinct plant families representing a range of site requirements and resource use efficiencies will test genetic influences on root morphological features; while growing distinct species with limiting or abundant resource levels will test if environmental factors affect genetic rankings.

Fine root acquisition of soil water and nutrients depends on root surface quantity and activity (Boyer 1985; Nye and Tinker 1977; Yanai et al. 1995). However, reported responses of root biomass and RLD to resource availability are inconsistent. The absolute amount of root biomass commonly increases in response to nutrients as plants increase in size (Fabião et al. 1995; Persson 1980), but other studies show absolute declines in root quantity (Gower et al. 1992) or relative declines compared to above ground tissues (Axelsson and Axelsson 1986). Forest growth process models commonly predict lower relative amounts of root tissue in response to high resource conditions (e.g. Landsberg and Waring 1997; Reynolds and Thornley 1982), yet observations are not always consistent with those predictions (Coyle and Coleman 2005). Defining primary production responses in relation to soil resource acquisition or understanding environmental controls of belowground carbon allocation requires greater understanding of root distribution under various levels of resource availability.

Gathering fundamental information on root distribution and activity has been hindered both by sampling difficulties and soil chemical and physical heterogeneity (Robinson 1994; Stewart et al. 1999). Variation among sampling locations ranging from 50 to well over $100 \%$ of fine-root quantity is frequently observed (e.g. Drexhage et al. 1999; Hendrick and Pregitzer 1992). Such large, ill-defined variability makes it difficult to distinguish among subtle controlling ecological factors. One way to distinguish between the quantity and activity of roots is to restrict observations to uniform soil and stand conditions. Uniformity can be accomplished by selecting sites with consistent soil, planted with similar genetic stock, and cultured to eliminate competing or understory vegetation. Such model forests are achieved in forest plantations (e.g. Adegbidi et al. 2004; Coleman et al. 2004b; Giardina et al. 2003; O'Grady et al. 2005). However, homogeneous soils are rare at scales sufficient to study forest stands. One way to evaluate the response to soil heterogeneity is to overlay systematic heterogeneity within a model forest and generate predictable patterns of resource distribution. Drip irrigation tubes used in intensive forest management operations create such a systematic pattern of resource heterogeneity (Fabião et al. 1995; Pronk et al. 2002; Ruiz-Sánchez et al. 2005), which will aid in defining the relative magnitude of genetic versus environmental controls over root distribution.

This paper reports the variation in root traits among tree species from various functional classes that were grown with limiting and abundant soil resources. One functional grouping includes those originating from resource rich sites and having narrow site requirements in comparison with species having more robust site requirements. Another grouping includes broadleaved deciduous species versus needle leaved evergreen species. These contrasting species were grown with a range of resource availability treatments applied using a drip irrigation. The species included are distinct in their growth habits, root morphology and nutrient use efficiency. The expectation is that accounting for commonly described spatial and temporal variation will make it possible to distinguish genetic and environmental effects.

It is hypothesized that resource availability treatments will increase the absolute amount of fine root biomass, and the drip tube treatment will create a systematic soil heterogeneity to which the roots will positively respond. Deciduous broadleaved species adapted to bottomland sites such as cottonwood and sycamore are expected to have smaller diameter roots with higher RLD and be much more responsive to resource availability than the more stress tolerant sweetgum and loblolly pine that have quite robust site requirements. Sweetgum is expected to have root characteristics that are similar to loblolly pine because they group together functionally based on their common robust site requirements, despite the fact that sweetgum is a broadleaved deciduous species similar to cottonwood and sycamore and is in that way distinct from pine. Furthermore, the high nutrient and water demands of cottonwood and sycamore are expected to show a much greater response to irrigation and fertilization treatments than sweetgum and pine both above and below ground. 


\section{Materials and methods}

The site, plant materials, and experimental design are described in detail by Coleman et al. (2004b). The following description presents factors relevant to the root biomass comparison reported here.

Site description and preparation

The experiment was conducted at the US Department of Energy Savannah River Site, a National Environmental Research Park located near Aiken, SC in the Carolina Sand Hill physiographic region $\left(33^{\circ} 23 \mathrm{~N}, 81^{\circ}\right.$ $\left.40^{\prime} \mathrm{E}\right)$. The soil is predominately a Blanton sand (thermic Grossarenic Paleudults), with a loamy subsoil at a depth of 120 to $200 \mathrm{~cm}$ across the site (Rogers 1990). Previous vegetation was plantation pine with an oak understory. Site preparation included debris removal and tilling. We piled slash with diameter greater than $15 \mathrm{~cm}$ off research plots and remaining debris, including stumps, was pulverized and incorporated to a depth of $30 \mathrm{~cm}$.

\section{Plant material}

Five tree genotypes of four species were included in this experiment: two eastern cottonwood (Populus deltoides Bartr.) clones (ST66, Issaquena County, MS, and S7C15, Brazos County, TX); American sycamore (Platanus occidentalis L., Westvaco orchard run); sweetgum (Liquidambar styraciflua L., family WV340); and loblolly pine (Pinus taeda L. family 756). Two cottonwood clones were used to give a broader genetic representation of the species. Bareroot sycamore, sweetgum and pine seedlings were hand planted during the first week of February 2000. Cottonwood cuttings were planted during the second week of April 2000.

\section{Experimental design}

Five tree genotypes were grown in three replicate blocks and received a range of resource availability treatments. Treatments consisted of control (C), irrigation (I), fertilization (F) and irrigation plus fertilization (IF). These treatments were designed to sequentially remove growth limitations and gain greater understanding of the biological potential for intensively managed forests in southeastern USA. Increased pulpwood and timber prices would make these treatments cost effective; however at current prices these treatments are not commercially viable. Within each block, all plots of a given genotype were grouped together as a whole-plot factor split into four treatment plots. Each treatment plot was $0.22 \mathrm{ha}$ in area and contained a central 0.04 ha measurement plot of 54 trees $(2.5 \times 3 \mathrm{~m}$ tree spacing $)$ surrounded by more than four border rows (minimum border width $12 \mathrm{~m}$ ). We used drip irrigation to apply up to $5 \mathrm{~mm}$ of water daily to meet evaporative demand. This quantity equals average regional daily evaporation for the period between April and October; therefore, the irrigation amount is designed to eliminate the evaporation deficit and assure favorable soil moisture. During the reporting period, average annual rainfall at the site was $982 \mathrm{~mm}$. An average of $494 \mathrm{~mm}$ of additional water was supplied to irrigated plots during each growing season. A complete and balanced liquid fertilizer was applied through the drip irrigation system. For cottonwood and sycamore, we applied fertilizer at rates of 40 and $80 \mathrm{~kg} \mathrm{~N} \mathrm{ha}^{-1} \mathrm{y}^{-1}$ in years 2000 and 2001 , respectively and at $120 \mathrm{~kg} \mathrm{~N} \mathrm{ha}^{-1} \mathrm{y}^{-1}$ in years 2002 and 2003. For pine and sweetgum, we applied $40 \mathrm{~kg}$ $\mathrm{N} \mathrm{ha}^{-1} \mathrm{y}^{-1}$ in 2000 and 2001, and $80 \mathrm{~kg} \mathrm{~N} \mathrm{ha}^{-1} \mathrm{y}^{-1}$ in 2002 and 2003. Fertilizer was increased annually in this manner to correspond with demand made by growing trees. Annual fertilizer treatments were split among 26 weekly applications between April and October. Split applications benefit tree growth and decrease $\mathrm{N}$ leaching and groundwater contamination compared with a single annual application (Axelsson and Axelsson 1986; Van Miegroet et al. 1994). Fertilizer application supplied enough water to deliver liquid fertilizer and flush drip tubes ( $5 \mathrm{~mm} /$ week). Control plots also received $5 \mathrm{~mm}$ water per week to assure there was no confounding of treatments. Thus, non-irrigated plots received $130 \mathrm{~mm}$ of additional water annually through the drip tubes. Herbicide was applied two or three times annually where necessary to eliminate the possibility of nontarget roots contaminating samples.

Fine and medium root biomass

We sampled fine ( $<1 \mathrm{~mm}$ diameter) and medium ( 1 to 5 $\mathrm{mm}$ diameter) root biomass at five systematic locations (Fig. 1) in each plot in November 2000-2003. November sampling was chosen because minirhizotron observations at this site (unpublished data) and other temperate sites with similar species indicate that 


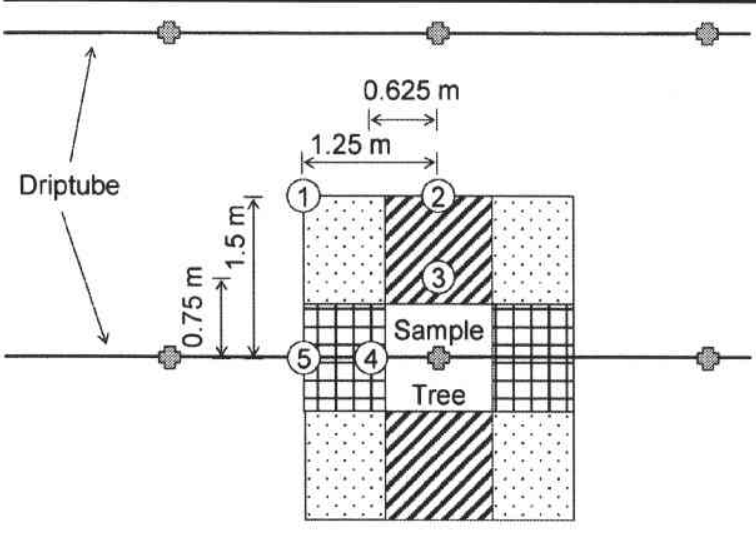

Fig. 1 Spatial arrangement of root sampling locations relative to sample tree. The center of numbered circles indicate locations for fine-root sample cores. One of the five locations was taken relative to five randomly selected trees per plot in each sampling year. Patterned rectangles indicate areas used for coarse root sampling: $\mathrm{A}$ - areas are grids, $\mathrm{B}$ - areas are diagonals, and $\mathrm{C}-$ areas are dots. Within each of the sampling areas a $50 \times 75 \mathrm{~cm}$ pit was randomly located and all coarse roots removed to $45 \mathrm{~cm}$ depth (no coarse roots were observed exiting to lower depths). Fine-root spatial models use horizontal dimensions as the $x$ parameter and vertical dimensions as the $y$ parameter

peak biomass occurs in autumn (Coleman et al. 2000). Samples were collected relative to tree stems and drip tubes at locations one-half and one-quarter the distance between adjacent trees, both along the irrigation drip line and perpendicular to the drip line. A fifth sample was collected at the center of the rectangle formed by the bases of four trees. These relative sample locations were selected to capture spatial heterogeneity in fine-root biomass that was expected to result from treatments supplied through the drip tube (cf. Burt and Styles 1994; Fabião et al. 1995; Ponder et al. 1984; Robinson 1994). In each of the 4 years, five different trees were randomly selected per plot and one of the five relative sample locations was randomly assigned to each. The aggregated average is expected to represent total biomass; however no comparison was made against completely random selection of locations. A $5 \mathrm{~cm}$ diameter corer was used to remove samples at soil depths of $0-15$ and $15-45 \mathrm{~cm}$ at each of the five locations, and a sample at 45-105 cm depth was removed at the location closest to the sample tree along the drip line (location 4). Through an oversight, roots of sweetgum were not sampled in 2002. Soil in core samples was washed away from roots by elutriation (Gillison's Variety Fabrication, Inc, Benzonia, MI). Live roots less than $5 \mathrm{~mm}$ diameter before drying were manually separated from dead organic matter, oven dried $\left(60^{\circ} \mathrm{C}\right)$ and weighed to the nearest $0.01 \mathrm{mg}$. Fine roots included those less than $1 \mathrm{~mm}$ diameter and medium roots were those between 1 and $5 \mathrm{~mm}$ diameter. Total root biomass at the stand level was determined for each plot by summing root biomass between 0 and 45 $\mathrm{cm}$ depths and then averaging the five sampling locations.

To better understand spatial root distribution and the potential for soil resource acquisition, the focus was on root density. Although root density can be expressed in terms of mass or length, root length is chosen here because it is the dimension commonly used to represent nutrient uptake capacity (Yanai et al. 1995). In 2003, root lengths were assessed for fine and medium root classes by means of flatbed scanner and WinRhizo image analysis software (Régent Instruments, Québec, Canada). Specific root lengths were determined and these values were used to convert biomass to root length for all years. Root length density for either fine or medium roots was then calculated as the product of root mass density and SRL divided by the core volume.

\section{Coarse root biomass}

We sampled coarse roots of cottonwood and sycamore in 2000, 2001 and 2002, and sweetgum and pine in 2001 and 2003 when sampling dormant whole-tree biomass. The intent was to define spatial distribution of roots relative to stem and drip tube locations, and to develop allometric relationships with stem dimensions. We sampled one or two trees per genotype per replicate plot. Sample trees were stratified based on diameter so that we included the entire size range within five trees sampled for each genotype by treatment combination. Coarse roots $(>5$ $\mathrm{mm}$ diameter) required larger sampling volumes because spatial variability was greater for coarse roots than for fine or medium roots. Furthermore, proximity to both tree stems and irrigation drip tubes was expected to affect the horizontal distribution of roots. To account for this expected heterogeneity, we defined three coarse-root-sampling areas for each selected tree: (A) adjacent to stump along the drip 
tube, (B) adjacent to stump between drip tubes, and (C) between four adjacent trees (Fig. 1). Within each of the three areas, we randomly selected one $0.375 \mathrm{~m}^{2}$ location of those possible in each area (4 for area A and 8 for areas $\mathrm{B}$ and $\mathrm{C}$ ), removed all roots greater than $5 \mathrm{~mm}$ diameter to a depth of $0.45 \mathrm{~m}$, and rinsed, dried $\left(60^{\circ} \mathrm{C}\right)$ and weighed them. No roots exiting the bottom of the sample location volumes exceeded the $5 \mathrm{~mm}$ coarse-root diameter criterion. Lateral roots in the $1 \mathrm{~m}^{2}$ area surrounding the stump are not included in this study of spatial distribution. The stump and attached lateral roots in the central square-meter were included in total belowground biomass and previously reported with aboveground biomass (Coyle and Coleman 2005).

\section{Aboveground growth}

Stem dimensions were used to calculate an index of stem volume. Dormant season height and diameter were measured for each of the 54 measurement plot trees following each growing season. Stem volume index was calculated for each tree as the product of tree height and the square of diameter at breast height ( $1.37 \mathrm{~m}$ from the ground surface). The volume of all live trees was summed for each plot and divided by the measurement plot area.

\section{Data analysis}

A repeated-measures analysis was used to assess changes in root biomass over time. Fine- and medium-root biomass were evaluated at the stand level with the individual treatment plot as the experimental subject; fertilization, irrigation and genotype were fixed factors; the experimental field block and treatments within block (whole-plot error term) were included as random factors and; plantation age was used as the repeated factor (Proc Mixed, SAS Institute Inc., Cary, NC). For coarse root biomass, sampling area illustrated in Fig. 1 was the experimental subject. The model was the same model as above except sampling area was added as a fixed factor. In each of the repeated measures analyses, the covariance structure was selected based on the lowest Corrected Akaike Information Criterion (AICC, Littell et al. 2006) and Kenward--Roger was specified for calculating denominator degrees of freedom. In every case the block and treatments-within-block random factors were not included in the final model because their variance component was estimated to be zero and could, therefore, be eliminated without impact (Littell et al. 2006). The experiment-wide error rate was set at $\alpha=0.01$ rather than $\alpha=0.05$ or 0.10 typical for such data. This was a subjective choice to avoid Type 1 errors caused by considering numerous factors and by the large number of samples.

Fourth-year RLD data analyzed with a split-block factorial design was used to assess fine root spatial distribution. To make it possible to assess horizontal and vertical spatial distribution, we included drip tube and depth factors, in addition to irrigation, fertilization and genotype. For the drip tube factor, sample locations 2 and 3 were a "no drip" category level, while locations 4 and 5 were a "drip" category level (see Fig. 1) so that every plot had two observations for each of the two drip tube factor levels. Sample location 1 was not included to maintain balance between drip tube factor levels. Treatments within block (whole-plot error term) were included as random factors. Experiment-wide error rate was again set at $\alpha=0.01$.

Proc Mixed (SAS Institute Inc., Cary, NC) was used to test for SRL differences among treatments, genotypes, depth and horizontal position. Tukey's HSD test was used to compare means.

A multiple stepwise regression procedure (Proc Reg, SAS Institute Inc. Cary NC) was used to investigate the spatial and temporal controls of fineRLD. The $x$-dimension was defined as the distance measured parallel to the drip line and the $y$-dimension was defined as the distance measured perpendicular to the drip line. The natural log transformed depth midpoint was included for each of the three depth categories. Genotypes were analyzed separately because such categorical information was inconsistent with the numerical regression approach. Parameter inclusion was at a significance level of $\alpha=0.10$.

\section{Results}

Root biomass and rooting density were affected by each of the factors tracked in this study including sampling year, genotype, vertical and horizontal distribution, as well as fertilization and irrigation treatments. Responses of medium roots were more variable than those of fine roots (e.g. compare $F$ values for significant effects in Table 1). Consequently, detailed responses will be presented for fine roots 
Table 1 Repeated measures analyses for total biomass of fine and medium roots ( 0 to $45 \mathrm{~cm}$ depth) during four establishment years

\begin{tabular}{|c|c|c|c|c|c|c|c|c|c|c|c|c|c|}
\hline \multirow[b]{2}{*}{ Effect } & \multirow[b]{2}{*}{$\mathrm{N} d f$} & \multicolumn{3}{|c|}{ Fine-root biomass } & \multicolumn{3}{|c|}{ Medium-root biomass } & \multicolumn{3}{|c|}{ Fine-RLD } & \multicolumn{3}{|c|}{ Medium-RLD } \\
\hline & & $\mathrm{D} d f$ & $F$ Value & $\operatorname{Pr}>F$ & $\mathrm{D} d f$ & $F$ Value & $\operatorname{Pr}>F$ & $\mathrm{D} d f$ & $F$ value & $\operatorname{Pr}>F$ & $\mathrm{D} d f$ & $F$ value & $\operatorname{Pr}>F$ \\
\hline$I$ & 1 & 36.3 & 8.43 & 0.0062 & 57.9 & 5.49 & 0.0226 & 55.7 & 6.91 & 0.0110 & 51 & 4.9 & 0.0314 \\
\hline$F$ & 1 & 36.3 & 28.44 & $<0.0001$ & 57.9 & 15.18 & 0.0003 & 55.7 & 32.01 & $<0.0001$ & 51 & 18.58 & $<0.0001$ \\
\hline$I \times F$ & 1 & 36.3 & 0.12 & 0.7321 & 57.9 & 0.15 & 0.6954 & 55.7 & 0.75 & 0.3897 & 51 & 0.15 & 0.6995 \\
\hline$T$ & 4 & 34 & 20.54 & $<0.0001$ & 59.5 & 5.07 & 0.0014 & 53.3 & 33.69 & $<0.0001$ & 53.1 & 4.78 & 0.0023 \\
\hline$I \times T$ & 4 & 34 & 1.25 & 0.3099 & 59.5 & 1.76 & 0.1489 & 53.3 & 1.28 & 0.2887 & 53.1 & 1.12 & 0.3571 \\
\hline$F \times T$ & 4 & 34 & 1.51 & 0.2205 & 59.5 & 2.27 & 0.0718 & 53.3 & 4.06 & 0.0060 & 53.1 & 2.24 & 0.0769 \\
\hline$I \times F \times T$ & 4 & 34 & 0.8 & 0.5352 & 59.5 & 1.37 & 0.2557 & 53.3 & 0.37 & 0.8304 & 53.1 & 1.09 & 0.3715 \\
\hline$Y$ & 3 & 112 & 322.08 & $<0.0001$ & 55.3 & 124.67 & $<0.0001$ & 112 & 267.05 & $<0.0001$ & 56.2 & 124.53 & $<0.0001$ \\
\hline$I \times Y$ & 3 & 112 & 1.91 & 0.1319 & 55.3 & 1.86 & 0.1467 & 112 & 1.60 & 0.1941 & 56.2 & 1.49 & 0.2264 \\
\hline$F \times Y$ & 3 & 112 & 8.65 & 0.0001 & 55.3 & 4.92 & 0.0042 & 112 & 10.09 & $<0.0001$ & 56.2 & 6.15 & 0.0011 \\
\hline$I \times F \times Y$ & 3 & 112 & 0.44 & 0.7239 & 55.3 & 1.18 & 0.3268 & 112 & 0.72 & 0.5394 & 56.2 & 1.23 & 0.3089 \\
\hline$T \times Y$ & 11 & 112 & 11.7 & $<0.0001$ & 75.7 & 5.32 & $<0.0001$ & 112 & 14.80 & $<0.0001$ & 77.2 & 5.05 & $<0.0001$ \\
\hline$I \times T \times Y$ & 11 & 112 & 2.11 & 0.0251 & 75.7 & 1.18 & 0.3182 & 112 & 2.57 & 0.0060 & 77.2 & 1.03 & 0.4311 \\
\hline$F \times T \times Y$ & 11 & 112 & 1.27 & 0.2532 & 75.7 & 1.35 & 0.2161 & 112 & 2.44 & 0.0092 & 77.2 & 1.41 & 0.1835 \\
\hline$I \times F \times T \times Y$ & 11 & 112 & 1.6 & 0.1070 & 75.7 & 1.63 & 0.1072 & 112 & 2.29 & 0.0146 & 77.2 & 1.75 & 0.0781 \\
\hline
\end{tabular}

Effects evaluated include irrigation $(I)$, fertilization $(F)$, genotype $(T)$ and sampling year $(Y)$. Analysis parameters shown include both numerator $(\mathrm{N} d f)$ and denominator ( $\mathrm{D} d f)$ degrees of freedom used for calculating the test statistic $(F$ value) and determining $\mathrm{P}$ values $(\operatorname{Pr}>F)$. Eleven covariate structures were ranked based on AICC values. The covariate structure selected here among eleven possible ones are Huynh-Feldt for fine roots and Heterogeneous Autoregressive for medium roots. Probabilities of $F<0.01$ considered statistically significant are indicated in bold typeface.

and more general responses for medium roots. The temporal responses are first explained at the plot level for the whole profile in order to compare effects of genotype, fertilization and irrigation treatments, and then within-plot spatial observations for the last observation year are presented to explain changes in vertical and horizontal distribution. Next, within-plot results are presented as an empirical model useful for
Fig. 2 Root biomass response to irrigation and fertilization over four growing seasons. Data include fine $(<1 \mathrm{~mm})$ and medium $(1$ to $5 \mathrm{~mm}$ ) roots between 0 and $45 \mathrm{~cm}$ depth. The two fertilization treatments are averaged within irrigation treatments on the left, and the two irrigation treatments are averaged within fertilization treatments on the right. Each bar is the mean \pm $\mathrm{SE}$ of five genotypes, two treatments and three replicate plots $(n=30)$
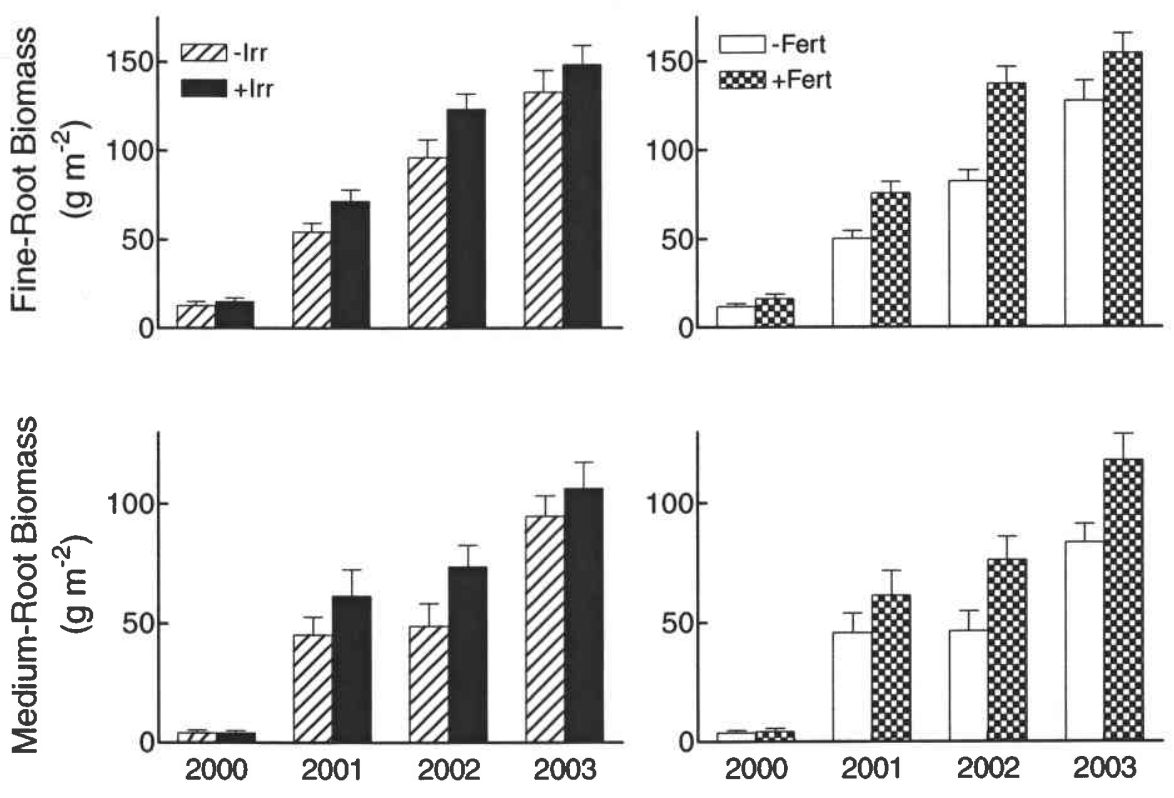
Fig. 3 Root density distribution by genotype for fine $(<1 \mathrm{~mm})$ (a) and medium (1 to $5 \mathrm{~mm}$ ) (b) root diameter classes. Data include RLD for roots sampled between 0 and $45 \mathrm{~cm}$ depth. Each bar is the mean \pm standard error of three replicate plots in four treatments $(n=12)$
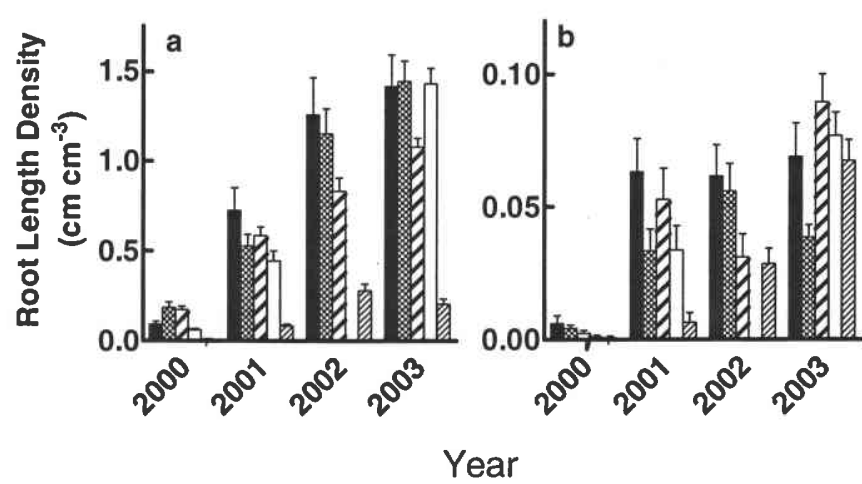

Cottonwood ST66

Cottonwood S7C15 ZZS Sycamore $\square$ Sweetgum IIII Loblolly Pine defining the relative importance of factors controlling fine-root density. Finally, effects of treatments on coarse root biomass are compared and spatial distribution patterns of larger roots are considered.

\section{Plot-level root responses}

Consistent root biomass patterns were found in response to treatments, genotypes and observation years. Fine root biomass increased with age, irrigation and fertilization (Fig. 2; Table 1). Biomass accumulation responded more to fertilization than to irrigation (see $F$ values in Table 1). Averaged across genotypes in 2003, fine-root biomass was $21 \%$ greater for fertilization than for the control and $12 \%$ greater for irrigation than for the control. Fertilizer response was large early in establishment and decreased over time (significant Fert X Year interaction), while few changes in irrigation responses over time were observed (nonsignificant Irr X Year).

Root biomass and RLD accumulation differed among genotypes (Fig. 3, Table 2). Average accumulation of fine-root biomass after four years was greatest in sweetgum and lowest in loblolly pine (Table 2). After four years, rankings for RLD were similar to those of biomass except that cottonwood and sweetgum values were greatest, sycamore was intermediate and loblolly pine was lowest. The response of fine-RLD to fertilization and irrigation differed temporally among genotypes (significant Irr $\mathrm{X}$ Type X Year and Fert X Type X Year interaction, Table 1). The response of cottonwood, particularly ST66, was much greater than that of other hardwoods and pine (Fig. 4).

Medium roots ranked differently among genotypes than fine roots (significant Type X Year interaction,
Table 1). After 4 years, average accumulation of medium root biomass was greatest for sycamore and lowest for cottonwood S7C15 (Table 2). The hardwood genotypes reached stable medium-root biomass levels much earlier than pine (Fig. 3). By 2001, the hardwoods had reached an average of $67 \%$ of their 2003 medium-root biomass, whereas pine had only reached $8 \%$. Both cottonwood genotypes reached $78 \%$ of their 2003 medium-root biomass by the 2001 sampling.

Spatial distribution

Root length density was used to assess spatial distribution differences. Calculating RLD requires information

Table 2 Root variables compared among genotypes in 2003

\begin{tabular}{llll}
\hline Genotype & Biomass $\left(\mathrm{g} \mathrm{m}^{-2}\right)$ & $\mathrm{SRL}(\mathrm{m} / \mathrm{g})$ & $\mathrm{RLD}\left(\mathrm{cm} \mathrm{cm}^{-3}\right)$ \\
\hline Fine root $(<1 \mathrm{~mm})$ & & & \\
CW ST66 & $140 \pm 18 \mathrm{~b}$ & $38.3 \pm 3.9 \mathrm{a}$ & $1.42 \pm 0.18 \mathrm{a}$ \\
CW S7C15 & $128 \pm 11 \mathrm{~b}$ & $42.7 \pm 5.3 \mathrm{a}$ & $1.44 \pm 0.12 \mathrm{a}$ \\
Sycamore & $163 \pm 8 \mathrm{~b}$ & $25.6 \pm 1.4 \mathrm{~b}$ & $1.08 \pm 0.05 \mathrm{~b}$ \\
Sweetgum & $210 \pm 10 \mathrm{a}$ & $24.8 \pm 0.7 \mathrm{~b}$ & $1.43 \pm 0.09 \mathrm{a}$ \\
Loblolly Pine & $64 \pm 10 \mathrm{c}$ & $12.3 \pm 1.3 \mathrm{c}$ & $0.20 \pm 0.03 \mathrm{c}$ \\
Medium root $(1 \mathrm{to} 5 \mathrm{~mm})$ & & \\
CW ST66 & $85 \pm 16 \mathrm{bc}$ & $3.2 \pm 0.5 \mathrm{a}$ & $0.07 \pm 0.01 \mathrm{abc}$ \\
CW S7C15 & $60 \pm 8 \mathrm{c}$ & $2.6 \pm 0.4 \mathrm{a}$ & $0.04 \pm 0.005 \mathrm{c}$ \\
Sycamore & $144 \pm 19 \mathrm{a}$ & $2.4 \pm 0.3 \mathrm{a}$ & $0.09 \pm 0.01 \mathrm{a}$ \\
Sweetgum & $115 \pm 15 \mathrm{ab}$ & $2.5 \pm 0.3 \mathrm{a}$ & $0.08 \pm 0.01 \mathrm{ab}$ \\
Loblolly Pine & $99 \pm 10 \mathrm{bc}$ & $2.7 \pm 0.3 \mathrm{a}$ & $0.07 \pm 0.01 \mathrm{bc}$ \\
\hline
\end{tabular}

Data are presented for biomass, specific root length (SRL) and root length density (RLD) for two root classes. Means \pm SE include four treatments with three replicate plots $(n=12)$. Among genotypes within root classes, those means followed by the same letter are not significantly different (Tukey's HSD, $\alpha=0.05$ ). 
Fig. 4 Fine root density response to fertilizer and irrigation treatments for five tree genotypes over four growing seasons. Data include roots sampled between 0 and $45 \mathrm{~cm}$ depth. Each bar is the mean \pm standard error of three replicate plots in four treatments $(n=12)$

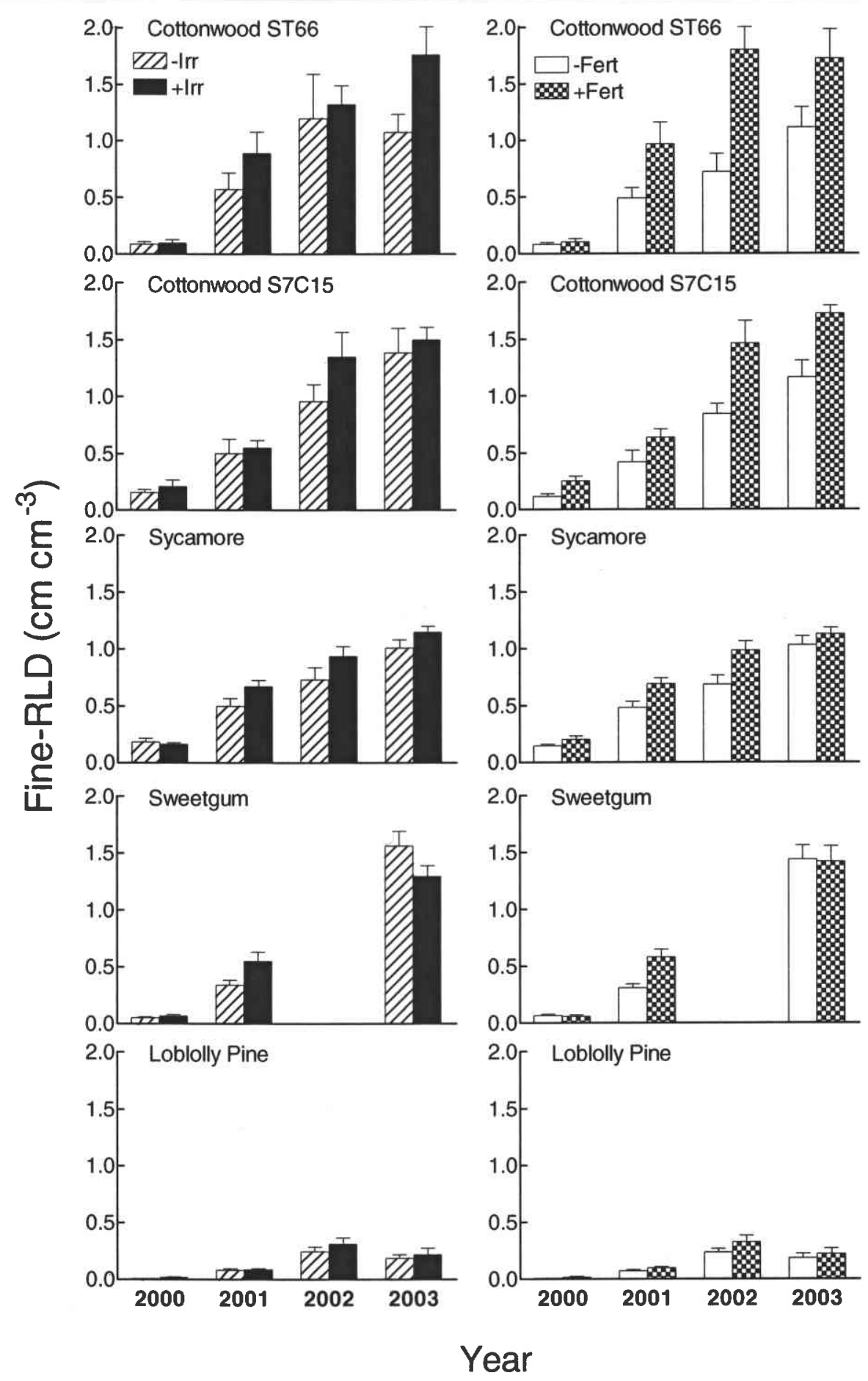

on root length per unit mass (SRL). Specific root length for fine roots was greatest for the two cottonwood genotypes and lowest for pine $(P<0.01$, Table 2) indicating that root diameters were relatively small for cottonwood and greater for pine. Medium-root SRL was lower than fine roots but SRL did not differ among genotypes $(P>0.59)$. Specific root length did not differ among the treatments for either root class $(P>0.11)$, nor did it differ between depths $(P>0.71)$ or horizontal position $(P>0.17)$. Due to the lack of 
treatment or spatial effects, mean SRL values for each genotype were used to scale from mass to RLD.

Root length density was dependent upon depth and position relative to the drip tube, especially when fertilizer was applied (Table 3). Root length density was greatest at the surface and in proximity to the drip tube. The response of medium roots was less complex than that of fine roots (i.e., no significant high order interactions). The response of medium roots under drip tubes was more than $60 \%$ greater with fertilizer than without it (Fig. 5). Fine-root RLD response to drip tube proximity varied with depth (Fig. 6). The response to drip tubes was greater in the top 0 to 15 $\mathrm{cm}$ layer of soil than in the 15 to $45 \mathrm{~cm}$ subsurface soil layer (significant Drip X Depth). These depth and drip tube responses were enhanced by the fertilizer treatment (significant Fert X Drip X Depth). A much greater fertilizer response was observed under the drip tube than away from the drip tube, but this was mostly evident at the surface; at depth, fertilizer had no apparent effect on fine-root RLD. Genotypes also differed in the magnitude of their fine-root RLD response to depth and relative drip tube position (significant Type X Depth and Type X Drip). The variable drip tube response among genotypes was dependent upon fertilizer level (Fert X Type X Drip). Cottonwood and sweetgum were more responsive to these factors than were sycamore and pine (Fig. 6).
Table 3 Analysis of variance results for fine and medium root length density in 2003
Effects evaluated include irrigation (I), fertilization (F), genotype (T), relative drip tube position (Dr) and depth (De). Data shown include both numerator ( $\mathrm{N} d f$ ) and denominator (D $d f$ ) degrees of freedom for calculating the test statistic ( $F$ value) and determining $P$ values $(\operatorname{Pr}>F)$. Probabilities of $F<0.01$ are in bold.

\begin{tabular}{|c|c|c|c|c|c|c|}
\hline \multirow[b]{2}{*}{ Effect } & \multirow[b]{2}{*}{$\mathrm{N} d f$} & \multirow[b]{2}{*}{$\mathrm{D} d f$} & \multicolumn{2}{|c|}{ Fine-RLD } & \multicolumn{2}{|c|}{ Medium-RLD } \\
\hline & & & $F$ Value & $\operatorname{Pr}>F$ & $F$ Value & $\operatorname{Pr}>F$ \\
\hline I & 1 & 40 & 3.55 & 0.0668 & 1.52 & 0.2245 \\
\hline $\mathrm{F}$ & 1 & 40 & 20.88 & $<0.0001$ & 11.42 & 0.0016 \\
\hline$I \times F$ & 1 & 40 & 0.20 & 0.6575 & 0.18 & 0.6754 \\
\hline$T$ & 4 & 40 & 45.32 & $<0.0001$ & 5.24 & 0.0017 \\
\hline$I \times T$ & 4 & 40 & 5.40 & 0.0014 & 1.15 & 0.3466 \\
\hline$F \times T$ & 4 & 40 & 4.19 & 0.0063 & 0.53 & 0.7169 \\
\hline$I \times F \times T$ & 4 & 40 & 1.31 & 0.2817 & 0.49 & 0.7403 \\
\hline Dr & 1 & 120 & 48.67 & $<0.0001$ & 22.53 & $<0.0001$ \\
\hline$I \times \mathrm{Dr}$ & 1 & 120 & 1.98 & 0.1616 & 0.28 & 0.5996 \\
\hline$F \times \mathrm{Dr}$ & 1 & 120 & 25.82 & $<0.0001$ & 10.58 & 0.0015 \\
\hline$I \times F \times \operatorname{Dr}$ & 1 & 120 & 0.72 & 0.3990 & 2.27 & 0.1349 \\
\hline$T \times \mathrm{Dr}$ & 4 & 120 & 4.63 & 0.0017 & 0.59 & 0.6731 \\
\hline$I \times T \times \mathrm{Dr}$ & 4 & 120 & 1.31 & 0.2719 & 0.78 & 0.5376 \\
\hline$F \times T \times \mathrm{Dr}$ & 4 & 120 & 4.35 & 0.0025 & 0.75 & 0.5630 \\
\hline$I \times F \times T \times \mathrm{Dr}$ & 4 & 120 & 2.61 & 0.0387 & 1.17 & 0.3258 \\
\hline $\mathrm{De}$ & 1 & 120 & 259.24 & $<0.0001$ & 39.51 & $<0.0001$ \\
\hline$I \times \mathrm{De}$ & 1 & 120 & 0.79 & 0.3748 & 0.91 & 0.3433 \\
\hline$F \times \mathrm{De}$ & 1 & 120 & 6.56 & 0.0117 & 2.07 & 0.1527 \\
\hline$I \times F \times \mathrm{De}$ & 1 & 120 & 0.16 & 0.6883 & 0.09 & 0.7658 \\
\hline$T \times \mathrm{De}$ & 4 & 120 & 14.51 & $<0.0001$ & 2.02 & 0.0964 \\
\hline$I \times T \times \mathrm{De}$ & 4 & 120 & 1.84 & 0.1260 & 0.45 & 0.7718 \\
\hline$F \times T \times \mathrm{De}$ & 4 & 120 & 2.24 & 0.0690 & 0.42 & 0.7935 \\
\hline$I \times F \times T \times \mathrm{De}$ & 4 & 120 & 0.36 & 0.8354 & 1.09 & 0.3641 \\
\hline $\mathrm{Dr} \times \mathrm{De}$ & 1 & 120 & 7.62 & 0.0067 & 1.90 & 0.1711 \\
\hline$I \times \mathrm{Dr} \times \mathrm{De}$ & 1 & 120 & 1.32 & 0.2527 & 0.28 & 0.5970 \\
\hline$F \times \operatorname{Dr} \times \operatorname{De}$ & 1 & 120 & 11.46 & 0.0010 & 4.18 & 0.0430 \\
\hline$I \times F \times \mathrm{Dr} \times \mathrm{De}$ & 1 & 120 & 0.10 & 0.7474 & 3.27 & 0.0731 \\
\hline$T \times \mathrm{Dr} \times \mathrm{De}$ & 4 & 120 & 2.25 & 0.0672 & 0.88 & 0.4773 \\
\hline$I \times T \times \mathrm{Dr} \times \mathrm{De}$ & 4 & 120 & 0.37 & 0.8303 & 0.29 & 0.8814 \\
\hline$F \times T \times \mathrm{Dr} \times \mathrm{De}$ & 4 & 120 & 2.94 & 0.0234 & 0.81 & 0.5212 \\
\hline$I \times F \times T \times \mathrm{Dr} \times \mathrm{De}$ & 4 & 120 & 1.88 & 0.1184 & 2.54 & 0.0431 \\
\hline
\end{tabular}




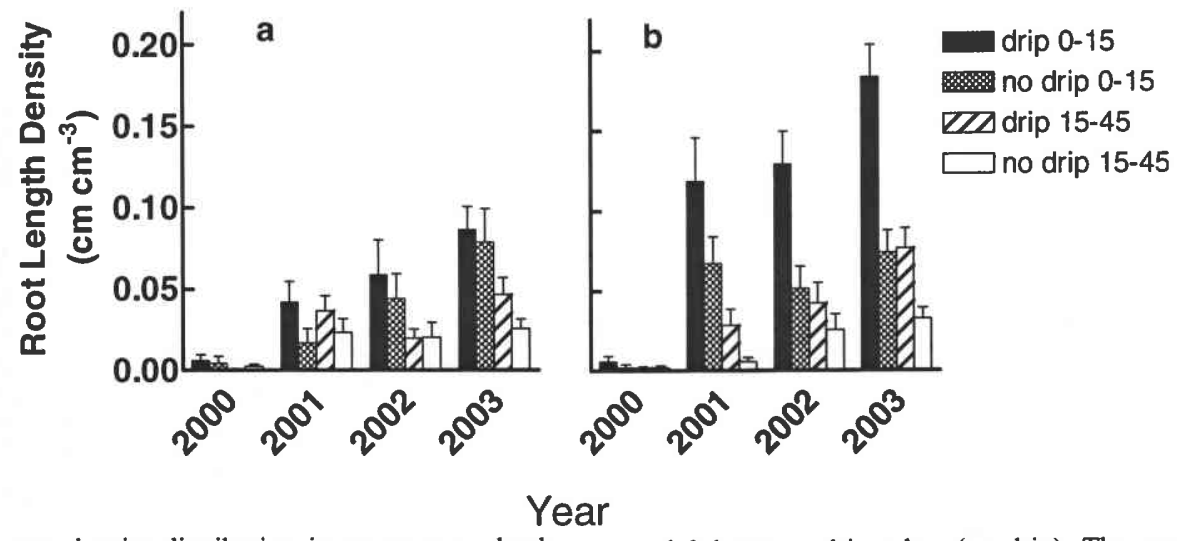

Fig. 5 Medium root density distribution in response to depth and relative drip tube position for non-fertilized (a) and fertilized (b) treatments. Sample locations 4 and 5 (see Fig. 1) under the drip tube (drip) were compared to sample locations 2

\section{Empirical model}

Empirical models of rooting density were developed for each of the genotypes so that the relative importance of controlling factors could be determined (Table 4). Factors included age, spatial distribution and treatments. For each genotype, age explained most of the variation in RLD (12 to $32 \%$ according to partial $R$-squared statistics) followed by depth ( 8 to $15 \%$ ) and the $y$-dimension ( 2 to $8 \%$ ). Age was positively correlated with RLD, while depth and $y$-dimension were negatively correlated; indicating that RLD declined with depth and distance from the drip tube.

Other factors explained additional variation in RLD, but lower than that of age, depth and the $y$ dimension; and they varied among genotypes. In both cottonwood genotypes and sycamore, fertilization and irrigation were the next most important factors, but these variables were not helpful in explaining sweetgum rooting density. Fertilization explained more variation in the data than did irrigation (1.3 to $3.5 \%$ vs 0.4 to $1.0 \%$ ). Both were positive indicating that fine-root biomass increased in response to resource availability. The $x$-dimension explained more RLD variation than did fertilization in loblolly pine and only a minor amount of variation in cottonwood ST66. However, $x$ did not explain more than $0.7 \%$ of the variation in RLD. When the $x$-dimension was included it was positive, which indicates that rooting increased with distance from the stem along the drip tube for cottonwood ST66 and loblolly pine. and 3 between drip tubes (no drip). The surface mineral soil layer $(0-15 \mathrm{~cm})$ was compared to the subsurface soil layer $(15-$ $45 \mathrm{~cm})$. Each bar is the mean \pm standard error of three replicate plots for five genotypes and two treatments $(n=30)$

\section{Coarse roots}

Coarse root biomass was controlled by stand age, sampling area and treatments $(P<0.005$; Table 5). Effects of irrigation, fertilization, sample area and their interaction differed between years $(P<0.009)$. Year explained nearly $18 \%$ of the variation in coarse root data, sample area explained an additional $4 \%$ and fertilization, irrigation and genotype each explained less than one percent $(0.7,0.6$ and $0.5 \%$, respectively). So, temporal and spatial factors have much greater control of coarse root biomass during stand establishment than do treatments or genotypes. Coarse-root biomass was typically greatest along the drip tube (A-sample area) and lowest in the diagonal direction between trees (C-sampling area; Fig. 7). The relative amount of coarse root mass between drip tubes (B-sample area) was dependent upon treatment (significant Fert X Area interaction). In some cases irrigated and fertilized plots had more than twice the coarse root biomass found in the controls (Fig. 8). The lack of interaction between genotype and treatments $(P>0.4)$ indicates that these average responses were quite consistent.

\section{Aboveground growth}

Stem volume index increased with time, fertilizer and irrigation (Fig. 9). More than a 30 -fold increase was observed in each of the genotypes between 2000 and $2003(P<0.001)$. Irrigation and Fertilization main effects were observed for the hardwood genotypes, 
Fig. 6 Fine-root density distribution in 2003 for five tree genotypes. Sample locations 4 and 5 (see Fig. 1) under the drip tube (drip) were compared to sample locations 2 and 3 between drip tubes (no drip). The surface mineral soil layer $(0-15 \mathrm{~cm})$ was compared to the subsurface soil layer $(15-45 \mathrm{~cm})$. Each bar is the mean \pm standard error of three replicate plots for irrigation treatments $(n=6)$. Bars topped by the same letter for each genotype are not significantly different (Tukey's HSD, $\alpha=0.05$ )

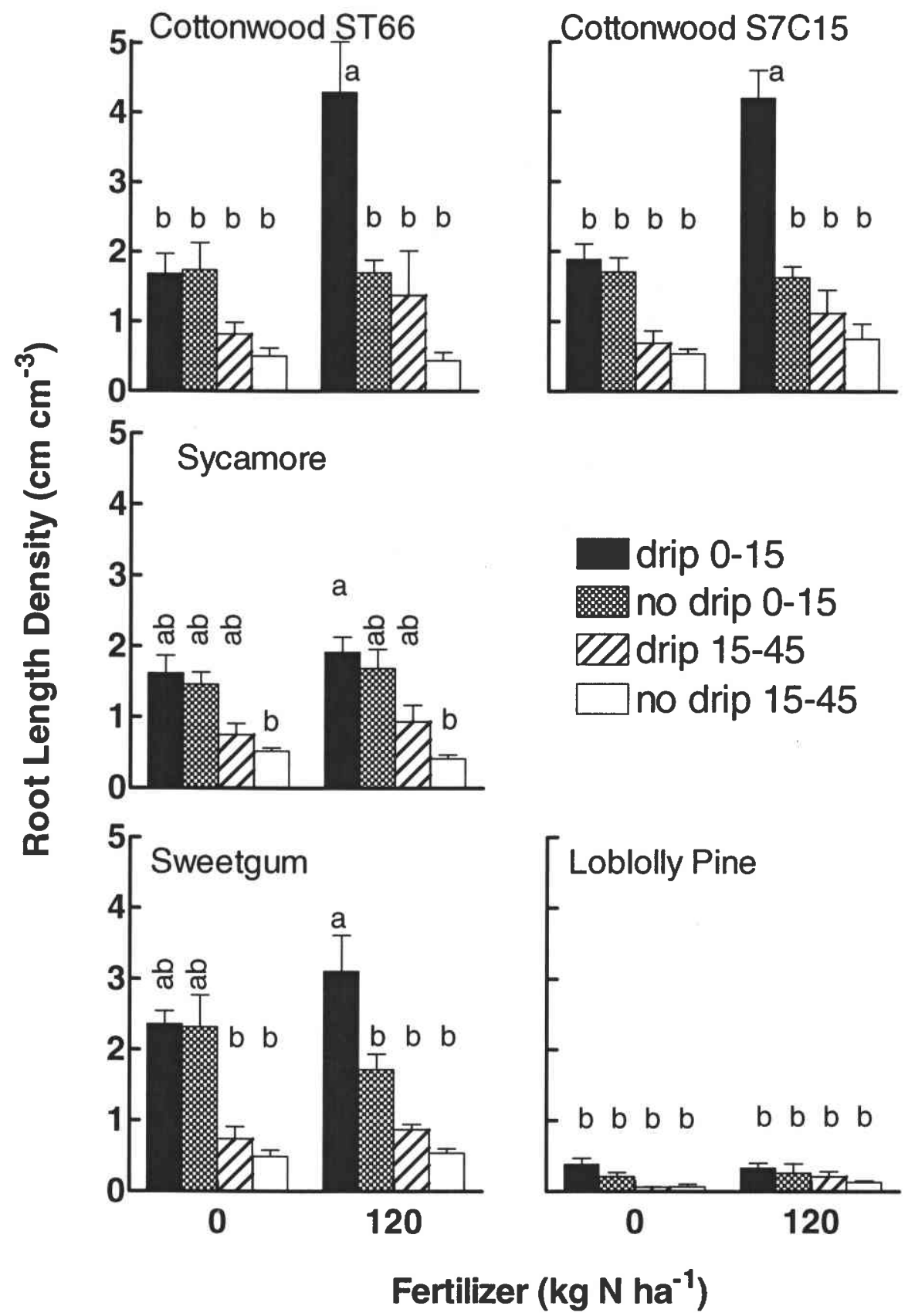

but pine was only affected by fertilization (significant Fert X Irr X Type interaction).

\section{Discussion}

Ranking among genotypes in root system characteristics were unaffected by resource availability and not entirely consistent with the functional forest types defined based on site requirements. Despite soil environmental conditions created by irrigation and fertilization treatments, cottonwood genotypes produced roots with consistently higher SRL (narrower diameter) and greater root length densities as expected from fast growing species originating from resource rich bottomland or alluvial sites (Comas and Eissenstat 2004; 
Table 4 Stepwise multiple regression results for fine-root density

\begin{tabular}{lllll}
\hline Parameter & $\begin{array}{l}\text { Parameter Estimate Cumulative } \\
\text { estimate }\end{array}$ & $\begin{array}{l}\text { Pr }>F \\
\text { standard model } R^{2} \\
\text { error }\end{array}$ & \\
\hline
\end{tabular}

Cottonwood ST66

$\begin{array}{lrlllll}\text { Intercept } & -0.3824 & 0.0478 & & & \\ \text { Age } & 0.1085 & 0.0111 & 0.12 & 70.44 & <0.0001 \\ \text { In (depth) } & -0.1666 & 0.0156 & 0.23 & 75.38 & <0.0001 \\ \text { Y } & -0.1426 & 0.0192 & 0.31 & 61.21<0.0001 \\ \text { Fert } & 0.0011 & 0.0002 & 0.34 & 28.14 & <0.0001 \\ \text { Irr } & 0.0696 & 0.0248 & 0.35 & 7.86 & 0.0052 \\ X & 0.0433 & 0.0239 & 0.36 & 3.27 & 0.0710\end{array}$

Cottonwood S7C15

Intercept $\quad-0.2951 \quad 0.0341$

Age $\quad 0.0963 \quad 0.0084$

In (depth) $-0.1356 \quad 0.0118 \quad 0.29$

$\begin{array}{llll}Y & -0.0921 & 0.0142 & 0.34\end{array}$

$\begin{array}{llll}\text { Fert } \quad 0.0007 & 0.0002 & 0.36\end{array}$

$\begin{array}{llll}\text { Irr } & 0.0352 & 0.0189 & 0.37\end{array}$

Sycamore

Intercept $\quad-0.2508 \quad 0.0313$

$\begin{array}{llll}\text { Age } & 0.1097 & 0.0078 & 0.22\end{array}$

ln (depth) $-0.1350 \quad 0.0109 \quad 0.35$

$\begin{array}{lllll}Y & -0.0996 & 0.0130 & 0.42\end{array}$

$\begin{array}{llll}\text { Fert } & 0.0005 & 0.0001 & 0.43\end{array}$

$\begin{array}{llll}\text { Irr } & 0.0455 & 0.0173 & 0.44\end{array}$

Sweetgum

Intercept $\quad-0.4400 \quad 0.0419$

$\begin{array}{llll}\text { Age } & 0.1719 & 0.0109 & 0.32\end{array}$

$\begin{array}{llll}\ln \text { (depth) } & -0.1956 & 0.0170 & 0.47\end{array}$

$\begin{array}{llll}Y & -0.0928 & 0.0204 & 0.50\end{array}$

Loblolly pine

$\begin{array}{lrrr}\text { Intercept } & -0.1669 & 0.0269 & \\ \text { Age } & 0.0581 & 0.0064 & 0.12 \\ \ln \text { (depth) } & -0.0705 & 0.0091 & 0.20 \\ Y & -0.0379 & 0.0112 & 0.22 \\ X & 0.0303 & 0.0139 & 0.23 \\ \text { Fert } & 0.0003 & 0.0001 & 0.23\end{array}$

Model statistics are for the complete model with all parameters previously entered. Genotypes were analyzed separately for clarity of trends.

Reich et al. 1998), however, since sycamore is also a bottomland species, it too was expected to share these characteristics with cottonwood and to be unique from sweetgum, a more stress tolerant species with robust site requirements. Yet SRL values of sycamore and sweetgum were equivalent and distinct from that of cottonwood. Furthermore, sweetgum RLD was equivalent to that of cottonwood and distinct from sycamore, indicating that root system characteristics of these species are not easily separated into functional classes based on site requirements. The distinction between broadleaved species and loblolly pine was consistent with expectations and with earlier observations (Coleman et al. 2000; Comas and Eissenstat 2004). The much lower root length and mass density of pine implies that it maintains a much lower root uptake surface. Equivalent or even greater growth rates for

Table 5 Repeated measures analysis results for total coarse root biomass

\begin{tabular}{|c|c|c|c|c|}
\hline Effect & $\mathrm{N} d f$ & $\mathrm{D} d f$ & $F$ Value & $\operatorname{Pr}>F$ \\
\hline$I$ & 1 & 296 & 9.64 & 0.0021 \\
\hline$F$ & 1 & 296 & 10.62 & 0.0013 \\
\hline$I \times F$ & 1 & 296 & 0.00 & 0.9451 \\
\hline$T$ & 4 & 300 & 3.32 & 0.0111 \\
\hline$I \times T$ & 4 & 300 & 1.01 & 0.4039 \\
\hline$F \times T$ & 4 & 300 & 0.39 & 0.8177 \\
\hline$I \times F \times T$ & 4 & 300 & 0.35 & 0.8459 \\
\hline$A$ & 2 & 297 & 34.21 & $<0.0001$ \\
\hline$I \times A$ & 2 & 297 & 3.97 & 0.0198 \\
\hline$F \times A$ & 2 & 297 & 11.84 & $<0.0001$ \\
\hline$I \times F \times A$ & 2 & 297 & 5.52 & 0.0044 \\
\hline$T \times A$ & 8 & 300 & 2.18 & 0.0289 \\
\hline$I \times T \times A$ & 8 & 300 & 0.40 & 0.9179 \\
\hline$F \times T \times A$ & 8 & 300 & 0.82 & 0.5859 \\
\hline$I \times F \times T \times A$ & 8 & 300 & 0.36 & 0.9420 \\
\hline$Y$ & 3 & 212 & 82.77 & $<0.0001$ \\
\hline$I \times Y$ & 3 & 212 & 4.73 & 0.0032 \\
\hline$F \times Y$ & 3 & 212 & 4.03 & 0.0082 \\
\hline$I \times F \times Y$ & 3 & 212 & 0.28 & 0.8383 \\
\hline$T \times Y$ & 5 & 139 & 0.57 & 0.7215 \\
\hline$I \times T \times Y$ & 5 & 139 & 1.54 & 0.1827 \\
\hline$F \times T \times Y$ & 5 & 139 & 0.53 & 0.7498 \\
\hline$I \times F \times T \times Y$ & 5 & 139 & 1.39 & 0.2301 \\
\hline$A \times Y$ & 6 & 205 & 8.75 & $<0.0001$ \\
\hline$I \times A \times Y$ & 6 & 205 & 1.95 & 0.0750 \\
\hline$F \times A \times Y$ & 6 & 205 & 3.49 & 0.0026 \\
\hline$I \times F \times A \times Y$ & 6 & 205 & 1.73 & 0.1159 \\
\hline$T \times A \times Y$ & 10 & 112 & 1.86 & 0.0585 \\
\hline$I \times T \times A \times Y$ & 10 & 112 & 2.24 & 0.0200 \\
\hline$F \times T \times A \times Y$ & 10 & 112 & 1.01 & 0.4368 \\
\hline$I \times F \times T \times A \times Y$ & 10 & 112 & 0.36 & 0.9606 \\
\hline
\end{tabular}

Effects evaluated include irrigation (I), fertilization (F), genotype (T), sampling area (A) (see Fig. 1) and sampling year (Y). Data shown include both numerator $(\mathrm{N} d f$ ) and denominator (D $d f$ ) degrees of freedom for calculating the test statistic ( $F$ value) and determining $P$ values $(\operatorname{Pr}>F)$. Data were analyzed using the SAS mixed model procedure. Year was used as a repeated measures factor. The autoregressive covariate structure used had the lowest AICC values of the 11 tested. Probabilities with $F<0.01$ are in bold. 
Fig. 7 Coarse root biomass spatial distribution for five tree genotypes. Spatially distinct sampling areas indicated by letters in the legend are described in Fig. 1. Each bar is the mean and standard error of three replicate plots averaged across two irrigation treatments $(n=6)$. Bars topped by the same letter for each genotype are not significantly different (Tukey's HSD, $\alpha=0.05$ )

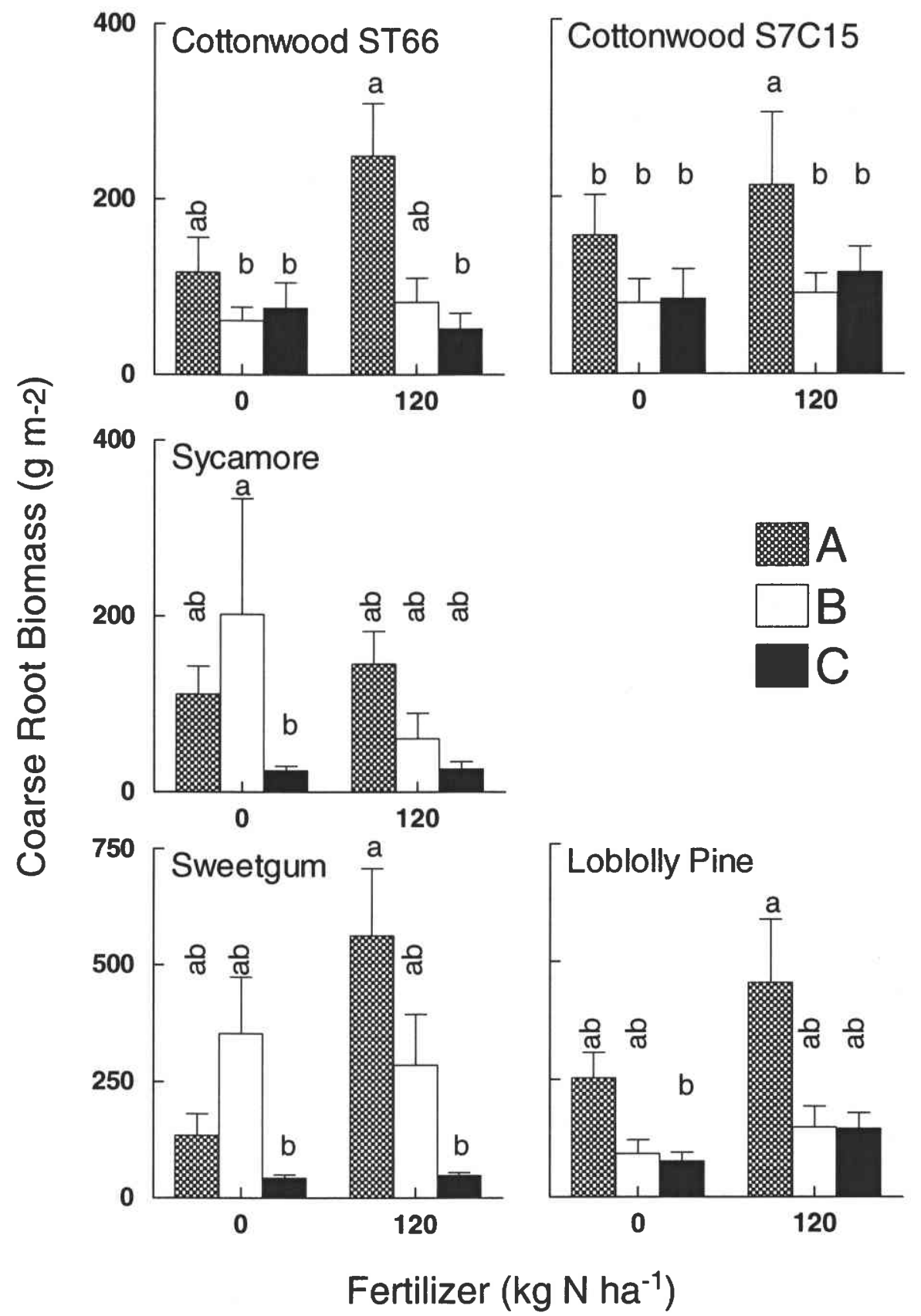

conifers than for hardwoods may be maintained by greater nutrient use efficiency (Binkley 1986) and reliance on mycorrhizal root symbionts for nutrient acquisition (Bauhus and Messier 1999).

There were important root system developmental differences among genotypes, irrigation and fertilization treatments. However, there were also much greater effects of age, depth, and location relative to the drip tube, which had to be evaluated for before genotype, fertilizer and irrigation effects could be evaluated. Many of the temporal, genotype and treatment differences observed in root biomass and RLD were initially related to overall tree growth, i.e. stand development. Figure 9 shows stem volume index changes during the root observation period considered in this report. During plantation establishment, stem growth was rapid as the stands occupied the site, genotypes occupied the site at different speeds, and high resource treatments resulted in 2 to 4 
Fig. 8 Coarse root biomass compared among treatments for each of the sampling dates. Genotypes are grouped by dates sampled: a both cottonwood clones and sycamore $(n=27)$, and b sweetgum and loblolly pine $(n=18)$. Each bar is the mean \pm standard error of three replicate plots, three relative drip line locations and the genotypes included

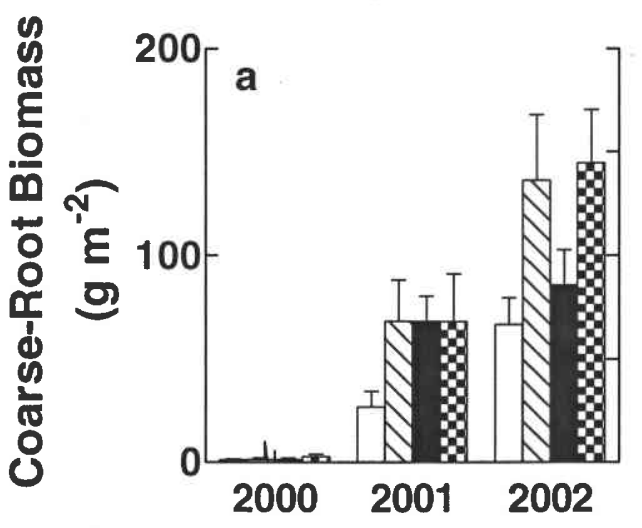

\section{Year}

fold differences in growth rates (Coleman et al. 2004a; Coyle and Coleman 2005). Therefore, to understand the effects of genotype, treatment and spatial factors on root systems, it is important to account for temporal variation.
Temporal variation

Age was the factor that most affected root biomass and density. Root length density was low for all genotypes
Fig. 9 Stem volume index $\left(\right.$ dia $^{2} \times$ ht) for each genotype during four growing seasons. Bars (means and standard error, $n=3$ ) labeled with the same letter within each genotypes in 2003 are not significantly different (Tukey's HSD, $\alpha=0.05$ )

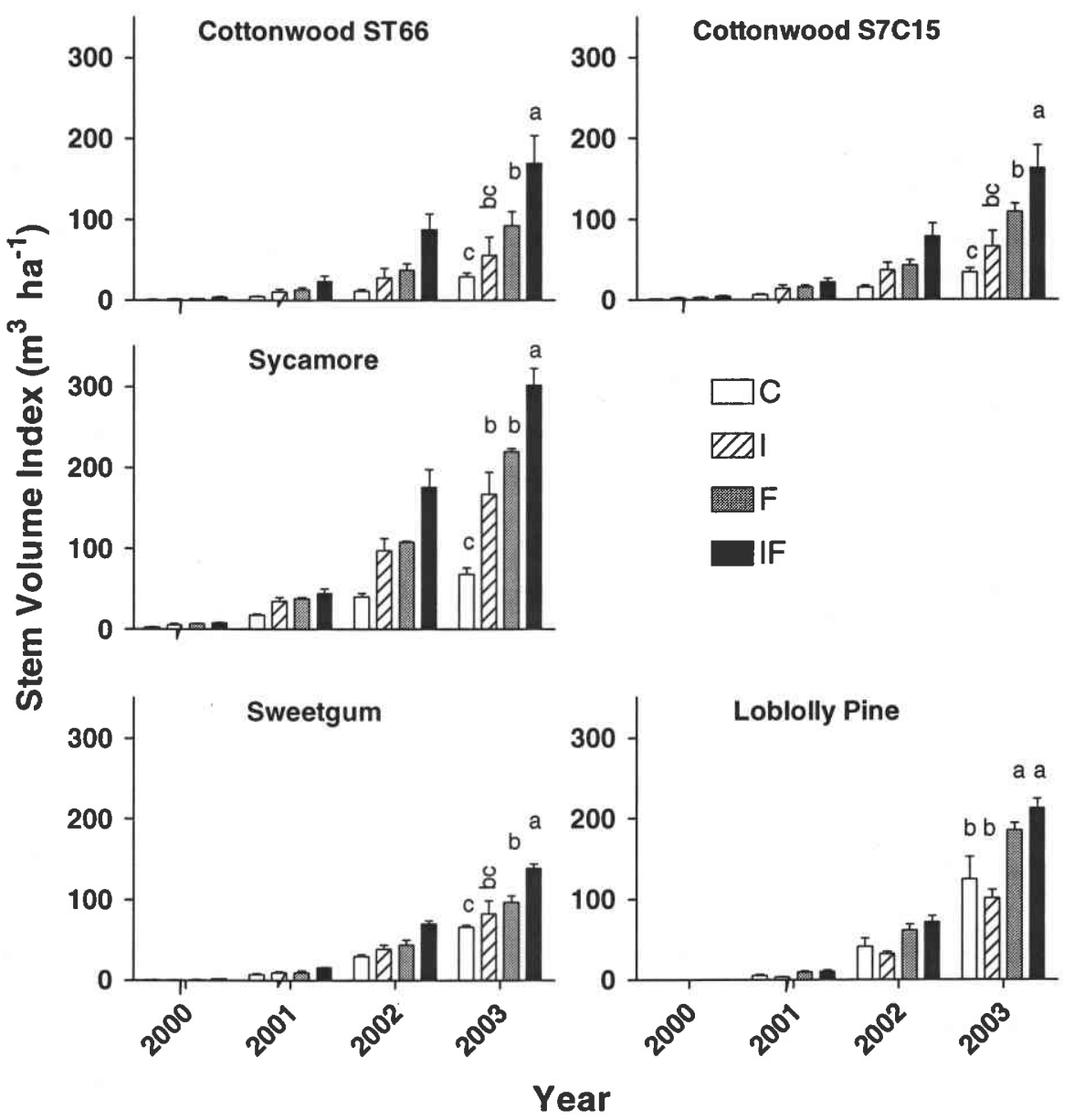


after the first growing season, but increased sharply by the second season. Although root system expansion and site occupation in establishing stands is expected, reports illustrating this process are limited. In most reports that consider root development, stumps and large roots are excavated in time series with individual trees showing remarkably consistent relationship between above and belowground biomass that varies little among taxa and environment (cf. Enquist and Niklas 2002). In a smaller number of studies, rooting density has been used to monitor site occupation by forest tree root system (Adegbidi et al. 2004; Bouillet et al. 2002; Hughes and Gandar 1993; Luxmoore et al. 1993; Misra et al. 1998; Nambiar 1983; O'Grady et al. 2005; Zutter et al. 1999). As in our work (Figs. 2 and 3), the soil volume is explored within the first one or two growing seasons, and stable root densities are reached by the third or fourth growing season. The predominant effect of age on root distribution in this study is likely due to the early stage of stand development under investigation. Once the site is fully occupied and the stand matures, such dramatic effects of age are expected to diminish. For instance, Vogt et al. (1987) found that there was little or no additional change in Douglas-fir root biomass after it reached a peak at canopy closure.

Our results indicate that treatments and genotypes continue to influence root biomass and RLD as stands age. Changes in treatment response over time suggest the magnitude of impact due to treatments is dependent on stand age. Genotype differences in response to fertilization suggest that some species are better able to take immediate advantage of favorable nutrient availability, while others have more conservative patterns of root-system development even when presented with favorable conditions (Fig. 4). However, in contrast to predictions, the more stress tolerant sweetgum was able to rapidly occupy the site at a rate equivalent to that of the two bottomland species and observed distinctions among genotypes in the timing of site occupation were restricted to hardwoods vs pine. To determine whether differences associated with nutrient availability stabilize or disappear over time, it will be necessary to study older stands.

\section{Vertical distribution}

Differences in vertical distribution of rooting density were more obvious than those in either horizontal dimension $(x$ or $y$ ). Fine-root mass density in the 0-15 $\mathrm{cm}$ soil layer was triple that in the $15-45 \mathrm{~cm}$ layer and differed among genotypes, which is consistent with other reported results. Decreased RLD at depth varies among species (Gale and Grigal 1987), environmental conditions (Lyr and Hoffmann 1967), ecosystems (Jackson et al. 1996), and whether trees are grown in mixed species or monoculture stands (Fredericksen and Zedaker 1995; Rothe and Binkley 2001; Zutter et al. 1999). Our results showing a greater response to drip tube enrichment in surface layers than at depth (Fig. 6) demonstrate that the relationship between RLD and depth is also altered by nutrient availability.

\section{Horizontal distribution}

Distinctions in horizontal distribution were largely caused by drip tubes. Rooting density declined with distance from the drip tube (y) in all genotypes, but rooting density did not decline with distance from tree stems along the drip tubes $(x)$. Drip tubes used for delivery of water and nutrient treatments consistently influence fine-root biomass and density in other woody species including Eucalyptus globulus Labill., Thuja occidentalis L. and Prunus armeniaca L. (Fabião et al. 1995; Pronk et al. 2002; Ruiz-Sánchez et al. 2005). Use of drip tubes to supply water and fertilizer creates heterogeneous soil conditions. Roots of tree seedlings grown with heterogeneous nutrient distribution in lab and greenhouse experiments show plasticity by proliferating in nutrient rich soil patches (Einsmann et al. 1999; Mou et al. 1997; Woolfolk and Friend 2003). Declining rooting density with distance from the drip tube demonstrates similar root plasticity in field conditions. Genotypes differed in their ability to proliferate roots under drip tubes (Table 3). Others have found root plasticity differences among species (e.g. Einsmann et al. 1999). The ability of cottonwood and sweetgum to proliferate roots under drip tubes that supply fertilizer, demonstrates that these species have a greater capacity to respond to soil heterogeneity than the others examined. However, as with other root characteristics mentioned above, sycamore and not sweetgum was expected to respond to heterogeneous nutrient availability in a manner similar to cottonwood. Given the ability to exploit high resource microsites, cottonwood and sweetgum are likely to take greater advantage of non-uniform resource distribution than the other species. These results do not consider plasticity in metabolism or symbiotic associations that 
may also be occurring (cf. Hodge 2004). Sycamore and loblolly pine may have particular advantages in exploiting soil resource heterogeneity through these other types of plastic responses.

Coarse roots also responded to heterogeneity created by the drip tubes (Fig. 7), indicating that regular delivery of water and nutrients at the same location in this manner shapes the whole tree root system, not just the fine roots. Use of drip irrigation, especially in sandy soils, causes cottonwood to align a majority of structural roots with drip tubes, while root distribution of sycamore remains relatively even (Randy Rousseau personal communication). Our results agree with these observations showing that coarse roots of cottonwood and pine are much more responsive to drip tubes than are coarse roots of sycamore. However, the contrasting response of sycamore and cottonwood indicate that coarse root plasticity is not a universal trait of bottomland hardwood species.

Stem stability may be lowered by coarse root proliferation along drip tubes. Some cottonwood genotypes are particularly susceptible to windthrow due to uneven distribution of large diameter roots around the tree (Harrington and DeBell 1996). Therefore plasticity due to heterogenous nutrient delivery by drip tubes may result in windthrow susceptibility, suggesting that care should be taken to orient drip tubes parallel to prevailing wind patterns. Furthermore, selecting varieties that produce numerous, smaller-diameter coarse roots would improve wind throw resistance.

There was some indication that rooting along the drip tubes actually increased with distance from the tree (positive $x$-dimension parameter for cottonwood ST66 and pine, Table 4). Such a response is most logically explained by overlapping with root systems of adjacent trees than by some morphological concentration of roots at greater distances from the tree stem.

\section{Resource availability}

Greater resource availability had a positive effect on root biomass and rooting density. Both fertilizer and proximity to drip tube increased root density (Fig. 6). Previous reports also show a positive response of RLD or root biomass to fertilization (Johnson 1990; Kubiske et al. 1998; Majdi 2001; Pregitzer et al. 2000). However, the influence of resources on root system expansion was small in comparison to the effect of temporal, spatial or genetic factors (Tables 4 and 5), and the magnitude of the response to resource availability was dependent upon the level of other factors (Figs. 2 and 6). For instance, the dramatic fertilization response observed in earlier growing seasons diminished in the fourth season (Figs. 2 and 4). Such temporal dampening of the response to resources and the relatively small response to resource availability compared with responses to spatial and temporal factors is an indication why it is difficult to generalize about fine root responses to resources (Hendricks et al. 1993; Joslin et al. 2000), and demonstrates the need to consider fine-root dynamics in response to numerous factors to identify even the direction of the response.

\section{Conclusions}

The predominate factors controlling RLD included stand development (age), depth and proximity to drip tubes. The influence of these factors had to be accounted for before the influence of resource availability and genotype could be determined. Although the influence of resource availability on RLD was a significant positive effect, it was small in comparison to temporal, spatial and genotype effects. Resource availability stimulated root production in parallel with shoot production and this was proportionally higher in soil enriched by drip tube irrigation. Fertilizer caused a greater response both above and belowground than did irrigation. The response to drip-tube applied fertilizer enrichment was greater in cottonwood and sweetgum indicating that these species had a greater ability to respond to heterogeneous nutrient availability than sycamore or loblolly pine. Genetic controls in root morphological characteristics, including SRL, RLD and RLD vs depth relationships, were consistent and not influenced by environmental characteristics. These root characteristics for loblolly pine were distinct from those of broadleaved deciduous species, and may relate to pine's relatively high tolerance of competition, drought resistance, nutrient use efficiency and dependence on mycorrhizal associates. However, distinctions between species having narrow site requirements compared with those having robust site requirements were not evident; demonstrating that there is a range of root strategies represented within these defined functional classes. 
Acknowledgments Funding was provided by the US Department of Energy-Savannah River Operations office through the USDA-Forest Service Savannah River and the Forest Service Southern Research Station under Interagency Agreement DEIA09-76SR00056; Department of Energy Oak Ridge National Lab Interagency Agreement 00-IA-11330135-221; Southern Research Station Research Work Units 4103, 4104, 4154, 4155, 4505,4703 , and The Timber Company, Weyerhaeuser, Champion International and Union Camp. David Coyle and Doug Aubrey provided technical assistance and manuscript review. Thanks to the many project technicians and staff at the USFSSavannah River Forest Station, The University of Georgia and Auburn University who made data collection possible. Helpful reviews were also provided by Alex Friend, Bernard Parresol, Felipe Sanchez, Alan Salmon and Ruth Yanai.

\section{References}

Adegbidi HG, Comerford NB, Jokela EJ, Barros NF (2004) Root development of young loblolly pine in spodosols in southeast Georgia. Soil Sci Soc Am J 68:596-604

Axelsson E, Axelsson B (1986) Changes in carbon allocation patterns in spruce and pine trees following irrigation and fertilization. Tree Physiol 2:189-204

Bauhus J, Messier C (1999) Soil exploitation strategies of fine roots in different tree species of the southern boreal forest of eastern Canada. Can J For Res 29:260-273

Binkley D (1986) Forest nutrition management. Wiley, New York, p 290

Bouillet JP, Laclau JP, Amaud M, M'Bou AT, Saint-André L, Jourdan C (2002) Changes with age in the spatial distribution of roots of Eucalyptus clone in Congo impact on water and nutrient uptake. For Ecol Manag $171: 43-57$

Boyer JS (1985) Water transport. Annu Rev Plant Physiol Plant Mol Biol 36:473-516

Burt CM, Styles SW (1994) Drip and microirrigation for trees, vines, and row crops. ITRC, Cal Poly, San Luis Obispo, CA

Chapin FS (1980) The mineral nutrition of wild plants. Annu Rev Ecol Syst 11:233-260

Chapin FS, Ruess RW (2001) Carbon cycle - the roots of the matter. Nature 411:749--752

Coleman MD, Dickson RE, Isebrands JG (2000) Contrasting fine-root production, survival and soil $\mathrm{CO}_{2}$ efflux in pine and poplar plantations. Plant Soil 225:129-139

Coleman MD, Coyle DR, Blake J, Britton K, Buford M, Campbell RG, Cox J, Cregg B, Daniels D, Jacobson M, Johnson K, McDonald T, McLeod K, Nelson E, Robison D, Rummer R, Sanchez F, Stanturf J, Stokes B, Trettin C, Tuskan J, Wright L, Wullschleger S (2004a) Production of short rotation woody crops grown with a range of nutrient and water availability: establishment report and first-year responses. USDA Forest Service, Southern Research Station, Asheville, NC, USA, General Technical Report, SRS-72, p 21

Coleman MD, Friend AL, Kern CC (2004b) Carbon allocation and nitrogen acquisition in a developing Populus deltoides plantation. Tree Physiol 24:1347-1357

Comas LH, Eissenstat DM (2004) Linking fine root traits to maximum potential growth rate among 11 mature temperate tree species. Funct Ecol 18:388-397
Connell MJ, Raison RJ, Khanna PK (1995) Nitrogen mineralization in relation to site history and soil properties for a range of Australian forest soils. Biol Fertil Soils 20:213-220

Coyle DR, Coleman MD (2005) Forest production responses to irrigation and fertilization are not explained by shifts in allocation. For Ecol Manag 208:137-152

Drexhage $M$, Chauvière $M$, Colin F, Nielsen CNN (1999) Development of structural root architecture and allometry of Quercus petraea. Can J For Res 29:600-608

Einsmann JC, Jones RH, Mou P, Mitchell RJ (1999) Nutrient foraging traits in 10 co-occurring plant species of contrasting life forms. J Ecol 87:609-619

Enquist BJ, Niklas KJ (2002) Global allocation rules for patterns of biomass partitioning in seed plants. Science 295:1517-1520

Fabião A, Madeira M, Steen E, Kätterer T, Ribeiro C, Araújo C (1995) Development of root biomass in an Eucalyptusglobulus plantation under different water and nutrient regimes. Plant Soil 168-169:215-223

Fitter AH (1991) The ecological significance of root system architecture: an economic approach. In: Atkinson D (ed) Plant root growth. An ecological perspective. Blackwell Scientific, Oxford, pp 229-243

Fredericksen TS, Zedaker SM (1995) Fine root biomass, distribution, and production in young pine-hardwood stands. New For 10:99-110

Gale MR, Grigal DF (1987) Vertical root distributions of northem tree species in relation to successional status. Can J For Res 17:829-834

Giardina CP, Ryan MG, Binkley D, Fownes JH (2003) Primary production and carbon allocation in relation to nutrient supply in a tropical experimental forest. Glob Chan Biol 9:1438-1450

Gower ST, Vogt KA, Grier CC (1992) Carbon dynamics of Rocky Mountain Douglas-fir: influence of water and nutrient availability. Ecol Monogr 62:43-65

Harley JL, Smith SE (1983) Mycorrhizal symbiosis. Academic, New York, p 483

Harrington CA, DeBell DS (1996) Above- and below-ground characteristics associated with wind toppling in a young Populus plantation. Trees-structure and Function 11:109118

Hendrick RL, Pregitzer KS (1992) Spatial variation in tree root distribution and growth associated with minirhizotrons. Plant Soil 143:283-288

Hendricks JJ, Nadelhoffer KJ, Aber JD (1993) Assessing the role of fine roots in carbon and nutrient cycling. Trends Ecol Evol 8:174-178

Hodge A (2004) The plastic plant: root responses to heterogeneous supplies of nutrients. New Phytol 162:9-24

Hughes KA, Gandar PW (1993) Length densities, occupancies and weights of apple root systems. Plant Soil 148:211-221

Jackson RB, Canadell J, Ehleringer JR, Mooney HA, Sala OE, Schulze ED (1996) A global analysis of root distributions for terrestrial biomes. Oecologia 108:389-411

Jobbagy EG, Jackson RB (2001) The distribution of soil nutrients with depth: global patterns and the imprint of plants. Biogeochemistry 53:51-77

Johnson JD (1990) Dry-matter partitioning in loblolly and slash pine: effects of fertilization and irrigation. For Ecol Manag 30:147-157 
Joslin JD, Wolfe MH, Hanson PJ (2000) Effects of altered water regimes on forest root systems. New Phytol 147:117-129

Kubiske ME, Pregitzer KS, Zak DR, Mikan CJ (1998) Growth and $\mathrm{C}$ allocation of Populus tremuloides genotypes in response to atmospheric $\mathrm{CO} 2$ and soil $\mathrm{N}$ availability. New Phytol 140:251-260

Landsberg JJ, Waring RH (1997) A generalised model of forest productivity using simplified concepts of radiation-use efficiency, carbon balance and partitioning. For Ecol Manag 95:209-228

Littell RC, Milliken GA, Stroup WW, Wolfinger RD (2006) SAS for mixed models. SAS Institute, Inc., Cary, NC, USA, p 633

Luo Y, Zhou X (2006) Soil respiration and the environment. Elsevier, Amsterdam, pp xi, 316, [314] of plates

Luxmoore RJ, Cunningham M, Mann LK, Tjoelker MG (1993) Urea fertilization effects on nutrient uptake and growth of Platanus occidentalis during plantation establishment. Trees-structure and function 7:250-257

Lyr H, Hoffmann G (1967) Growth rates and growth periodicity of roots. Int Rev For Res 2:181-236

Majdi $H$ (2001) Changes in fine root production and longevity in relation to water and nutrient availability in a Norway spruce stand in northern Sweden. Tree Physiol 21:10571061

Misra RK, Turnbull CRA, Cromer RN, Gibbons AK, LaSala AV (1998) Below- and above-ground growth of Eucalyptus nitens in a young plantation. I. Biomass. For Ecol Manag 106:283-293

Mou P, Jones RH, Mitchell RJ, Zutter B (1995) Spatialdistribution of Roots in sweetgum and loblolly-pine monocultures and relations with aboveground biomass and soil nutrients. Funct Ecol 9:689-699

Mou P, Mitchell RJ, Jones RH (1997) Root distribution of two tree species under a heterogeneous nutrient environment. J Appl Ecol 34:645-656

Nambiar EKS (1983) Root development and configuration in intensively managed radiata pine plantations. Plant Soil $71: 37-47$

Nye PH, Tinker PB (1977) Solute movement in the soil-root system. Blackwell, Oxford, p 342

O'Grady AP, Worledge D, Battaglia M (2005) Temporal and spatial changes in fine root distributions in a young Eucalyptus globulus stand in southern Tasmania. For Ecol Manag 214:373-383

Patra AK, Jarvis SC, Hatch DJ (1999) Nitrogen mineralization in soil layers, soil particles and macro-organic matter under grassland. Biol Fertil Soils 29:38-45

Persson H (1980) Fine-root dynamics in a Scots pine stand with and without near-optimum nutrient and water regimes. Acta Phytogeogr Suec 68:101-110

Ponder HG, Gilliam CH, Evans CE (1984) Trickle irrigation of field-grown nursery stock based on net evaporation. Hortscience 19:304-306
Pregitzer KS, Zak DR, Maziasz J, DeForest J, Curtis PS, Lussenhop J (2000) Interactive effects of atmospheric $\mathrm{CO}_{2}$ and soil-N availability on fine roots of Populus tremuloides. Ecol Appl 10:18-33

Pregitzer KS, DeForest J, Burton AJ, Allen MF, Ruess RW, Hendrick RL (2002) Fine root architecture of nine North American trees. Ecol Monogr 72:293-309

Pronk AA, De Willigen P, Heuvelink E, Challa H (2002) Development of fine and coarse roots of Thuja occidentalis 'Brabant' in non-irrigated and drip irrigated field plots. Plant Soil 243:161-171

Reich PB, Walters MB, Tjoelker MG, Vanderklein D, Buschena $C$ (1998) Photosynthesis and respiration rates depend on leaf and root morphology and nitrogen concentration in nine boreal tree species differing in relative growth rate. Funct Ecol 12:395-405

Reynolds JF, Thornley JHM (1982) A shoot:root partioning model. Ann Bot 49:585-597

Robinson D (1994) The responses of plants to non-uniform supplies of nutrients. New Phytol 127:635-674

Rogers VA (1990) Soil survey of savannah river plant area, parts of Aiken, Barnwell, and Allendale counties, South Carolina. USDA Soil Conservation Service, Washington, DC

Rothe A, Binkley D (2001) Nutritional interactions in mixed species forests: a synthesis. Can J For Res 31:1855-1870

Ruiz-Sánchez MC, Plana V, Ortuño MF, Tapia LM, Abrisqueta JM (2005) Spatial root distribution of apricot trees in different soil tillage practices. Plant Soil 272:211-221

Ryan MG, Law BE (2005) Interpreting, measuring, and modeling soil respiration. Biogeochemistry 73:3-27

Stewart JB, Moran CJ, Wood JT (1999) Macropore sheath: quantification of plant root and soil macropore association. Plant Soil 211:59-67

Trumbore S (2006) Carbon respired by terrestrial ecosystems recent progress and challenges. Glob Chang Biol 12:141-153

Van Miegroet H, Norby RJ, Tschaplinski TJ (1994) Nitrogen fertilization strategies in short-rotation sycamore. For Ecol Manag 64:13-24

Vogt KA, Vogt DJ, Moore EE, Fatuga BA, Redlin MR, Edmonds RL (1987) Conifer and angiosperm fine-root biomass in relation to stand age and site productivity in Douglas-fir forests. J Ecol 75:857-870

Waring RH, Schlesinger WH (1985) Forest ecosystems. Academic, Orlando, p 340

Woolfolk WTM, Friend AL (2003) Growth response of cottonwood roots to varied $\mathrm{NH}_{4}: \mathrm{NO}_{3}$ ratios in enriched patches. Tree Physiol 23:427-432

Yanai RD, Fahey TJ, Miller SL (1995) Efficiency of nutrient acquisition by fine roots and mycorrhizae. In: Smith WK, Hinckley TM (eds) Resource physiology of conifers. Academic, San Diego, pp 75-103

Zutter BR, Mitchell RJ, Glover GR, Gjerstad DH (1999) Root length and biomass in mixtures of broomsedge with loblolly pine or sweetgum. Can J For Res 29:926-933 
